\title{
The Social Context of Economic Decisions*
}

\author{
George J. Mailath \\ Andrew Postlewaite ${ }^{\dagger}$ \\ University of Pennsylvania \\ University of Pennsylvania
}

September 20, 2002

\begin{abstract}
The social context can have a large impact on economic decisions. The theoretical challenge is to formulate a model that encompasses both social and economic decisions in a meaningful manner. We discuss the incorporation of social context into neoclassical economic models using social institutions. We also discuss the relationship between social institutions, social capital, and the social value of assets (introduced by Mailath and Postlewaite (2002)). Keywords: Social Capital, Social Assets, Social Institutions. JEL Classification Codes: Z13
\end{abstract}

\section{Introduction}

It is widely accepted that the social context within which economic decisions are made can have a large impact on those decisions. Social context matters for several reasons: first, individuals may care about some social characteristics, such as status, honor, or popularity; second, preferences may be influenced by the environment; finally, even if individuals have exogenous preferences only over "economic" variables, the nature of interactions that facilitate economic activity can themselves be at least partially social in nature.

The social context must be taken into account when studying many applied economic problems. If status, honor or popularity are important to an individual, predictions about labor market response to taxes or bonuses that ignore these considerations will be less accurate than predictions that consider these factors. Any serious investigation into the affect that the social context has on economic decisions requires a theory as to the nature of the interaction between the two.

\footnotetext{
* Prepared for the European Economic Association 2002 Congress.

${ }^{\dagger}$ Department of Economics, University of Pennsylvania, Philadelphia, Pennsylvania 19104. Tel.: 215/898-7350; fax: 215/573-2057; email: apostlew@econ.upenn.edu
} 
Understanding and modelling the social context of economic decisions is a distinct enterprise from the economic analysis of social decisions (such as the economics of crime and marriage). While the latter work demonstrates the value of expanding the scope of traditional economic analysis, it does not directly provide insight into modelling social context. The economic analysis of social decisions succeeds by studying social phenomena (those once thought beyond the scope of traditional economics) using models satisfying neoclassical assumptions. In contrast, modelling the social context may require nonstandard preferences or endogenous preferences. ${ }^{1}$ Models that deviate from the neoclassical paradigm certainly provide insights into particular problems. We will show that, as in the economic analysis of social decisions, it is also possible to provide insights into some problems centrally involving a social context without deviating from the neoclassical paradigm with respect to preferences. The challenge is to formulate a model that encompasses social and economic decisions in a sensible manner, and at the same time allows for a distinction.

This challenge is a difficult one. When is a decision economic rather than social? While many anonymous interactions in a competitive market are clearly economic, other decisions that seem economic have social elements. For example, the long run relationship between an upstream and a downstream firm with moral hazard aspects is clearly economic. On the other hand, we could interpret this as a long-run "trust" or "favor" relationship. Are the Maghribi traders studied by Greif (1993) involved in an economic or a social interaction? While we cannot as yet provide a formal distinction between economic and social decisions, we describe here examples in which the distinction is clear.

Groups in a society often have shared values, shared notions of acceptable behavior, and mechanisms to encourage or impose standards of acceptable behavior. A group's shared values, acceptable behaviors, and enforcement mechanisms constitute the social institutions for the group. We formalize this idea as: if all (or most) individuals of a group behave in accordance with the same principle, then that group has a social institution governed by that principle. Moreover, if that behavior is an equilibrium, then the social institution governed by that principle is an equilibrium phenomenon. This notion captures property rights regimes, formal and informal legal structures, as well as class structures.

This framework underlies Cole, Mailath, and Postlewaite (1992) (hereafter CMP1) and Cole, Mailath, and Postlewaite (1998) (hereafter CMP2), which analyze a dynastic growth model with men and women who match and have children. After matching, they

\footnotetext{
${ }^{1}$ An example of the former is Becker (1991), who examines how the utility that individuals get from a restaurant meal may be affected by the number of other diners. Two examples of the latter are Bisin and Verdier (2000), who study a model in which individiduals take into account the affect of their choices on their children's preferences about religion, and Fernandez, Fogli, and Olivetti (2002), who argue that a woman's education and labor choices affect her son's preferences over women.
} 
allocate their endowment between their own consumption and a bequest to their male offspring, whose consumption enters parents' utility function. Differences in the ways that men and women (optimally) match can be viewed as different social institutions. ${ }^{2}$

The primary aim of CMP1 is to illustrate how, within a given economic environment, differences in social institutions are associated with distinct savings and investment patterns. It is assumed in that paper that consumption of matched couples is joint, hence men and women both prefer wealthier mates to less wealthy mates, ceteris paribus. In one type of matching, wealthier men match with wealthier women. When wealthier men match with wealthier women, there is an incentive for parents to leave larger bequests. Larger bequests make their male offspring more desirable, and hence able to attract a wealthier mate; since consumption is joint, this increases the son's utility. This generates a competition among dynasties that leads to larger bequests than in the case of a dynastic growth model without the matching component.

In addition to this equilibrium, CMP1 discusses a second social institution consistent with optimizing agents, which they termed "aristocratic" matching. Here, there is an exogenous "social ranking" of dynasties, and sons inherit the rank of their father. It is proposed that the wealthiest women match with the men who rank highest in the social ordering, even if these men are not the wealthiest men. There is a question about the incentive compatibility of such a proposed matching: Why would a wealthy woman match with a less wealthy man than she could attract simply because of an artificial social rank? The answer is that such a proposed matching rule might be incentive compatible: a woman who matches with a higher ranking man knows that the son of a high ranking man will inherit the rank, and will attract a wealthy mate in such a ranking. Women who put positive weight on the welfare of their offspring will sometimes find the bargain attractive. This second matching arrangement is interesting because it eliminates the tournament-like competition among dynasties; when the men who match with the wealthiest women are those born of high rank, the bequest a couple leaves to their son will no longer affect his match. The decreased incentive for a matched couple to bequeath wealth to their sons leads to a lower growth rate in societies that are governed by this aristocratic matching system than in societies governed by the "wealth-is-rank" matching system.

However, the incentive compatibility of such a social institution is fragile. Incentive compatibility of the social institution of aristocratic matching requires that even for very low ranked agents, the possibility of one's descendants losing rank suffices to prevent opportunistic behavior (in particular, oversaving in an attempt to improve a match). In general, one would not expect this to hold (see Landsburg (1995) and Cole, Mailath, and Postlewaite (1995)). Indeed, this is an important insight from that work. In CMP2, other social institutions are studied that address the fragility of the aristocratic

\footnotetext{
${ }^{2}$ In other work, we have used the term "social arrangements" to describe these differences.
} 
matching. In particular, it is in general true that the social institution where high ranked agents match according to the aristocratic matching, while low ranked follow the "wealth-is-status" matching (with an appropriate mixing for middle ranked) is incentive compatible.

In our view, social capital is created by society's social institutions. In the examples above, there may be two distinct social institutions that can govern the matching within a society, and agents' behavior differs markedly depending on what social institution is in place. When the social institution governing matching is wealth-is-rank, parents consume less and bequeath more than when the social institution governing matching is aristocratic.

When there is a range of possible social institutions, assets no longer have a value that is necessarily independent of the governing institution. Since different social institutions can create different incentives for a variety of economically relevant behaviors and decisions, assets that have little (or no) value under some social institutions may have positive value under others. Mailath and Postlewaite (2002) (hereafter MP) illustrates this point. MP analyze a model in which individuals with identical costs make human capital investments that depend on the social institutions governing matching. MP introduce the notion of the "social value" of an asset. An agent may have a number of assets, the possession of which lead to higher utility than would be possible without them. Examples include both alienable assets that can be transferred to other people such as machines or money, and inalienable assets that cannot be transferred - human capital. For a fixed set of preferences and technology, an asset may or may not have productive value. A machine that can produce radios and a bel canto ("beautiful singing") voice both have productive value. Other assets may not have direct productive value, yet the possession of them may lead to higher utility. For example, it may be that in a particular society agents with lighter skin or a particular accent enjoy higher consumption than those with darker skin or a less desirable accent, even if those attributes have no productive value per se. The social value of an asset is that part of an asset's value that stems from the social institutions, that is, the part of the value beyond what is attributable to the asset's productive value. We next describe how the model with social assets.

\section{Social Value of Assets}

Consider a generational model in which men and women match and have children. Men and women jointly consume their endowments. People get utility from their own consumption and their descendants' consumption. Individuals' sole decision is whom to match with, and since consumption is joint, people prefer wealthier partners. There will trivially be an equilibrium in which each person's wealth determines completely his or her match. 
MP show that in addition to equilibria of this kind, there may be additional equilibria in which nonproductive attributes affect matching. In particular, in equilibrium, attributes that have no fundamental value can have instrumental value. Individuals care about their children's consumption, which depends on the children's' (random) income. It is assumed that it is impossible to insure against this risk; this missing market allows the possibility that social arrangements may arise that ameliorate the resulting inefficiency.

Suppose that there is a heritable attribute that is independent of income, height for example, and suppose further that the attribute does not enter people's utility functions. Suppose that, nevertheless, in this society tall people are considered desirable mates, that is, that people are willing to match with a tall person with slightly less income than a short person. In such a society, people will naturally prefer their children to be tall since, all else equal, they consume more. But if they prefer tall children, and height is a heritable attribute, they will naturally prefer tall mates. In other words, a preference for tall mates may be self-fulfilling. Notice that this has nothing to do with any intrinsic desirability for tall people; within this same society it could equally well have been that shortness was a desirable attribute. Any heritable attribute might serve as a social asset in this way.

If the social arrangements make height a desirable attribute, we see that the degree of assortativeness of matching on wealth is decreased relative to the case that matching is on wealth alone. When there is no such desirable attribute, wealthy men match only with wealthy women and vice versa. When the social arrangements value an attribute such as height, some wealthy short people match with tall less wealthy people. The consequence of social arrangements that value such assets is that the variance of consumption in society is lower. When people are risk averse, the social arrangements that value attributes that are fundamentally extraneous can be welfare superior to arrangements that ignore such extraneous attributes.

\subsection{Formal Model}

There is an infinite sequence of two-period lived agents, each of which consists of a continuum of men and women. There is a single non-storable consumption good. In each period, old men and women match and consume their combined wealth (so that the good is a public good within couples). In addition, each couple has two offspring. The common consumption utility function for old agents is concave and denoted $U: \Re \rightarrow \Re$. Individuals care about their descendants' welfare: the utility to any matched couple is their utility from consumption plus the discounted average utility of their children, with common discount rate $\beta$. This means, of course, that their utility depends on the consumption of all future generations.

While agents neither take actions nor receive utility in their first period of life, 
they may acquire an attribute. We assume that agents can only acquire this attribute through their parents: both offspring will have the attribute for sure if both parents possess the attribute, they will surely not have it if neither have it, and they will have it with probability $1 / 2$ if one parent had the attribute. For simplicity, it is assumed that either both offspring have the attribute, or neither does. Individuals with the attribute are $y$ agents, while those without the attribute are $n$ agents. This attribute does not enter into agents' utility functions. The transmission of the attribute may be thought of as genetic and the attribute a characteristic like height, or as an attribute that is culturally transmitted, such as an accent.

Each agent receives an endowment of the consumption good (income) at the beginning of their second period of life. This income is either high $(H)$ or low $(L)$. MP assume an agent's income is independent of the parents' incomes. Possible consumption levels for matched pairs are $2 H, 2 L$ and $H+L$. Agents are equally likely to have high or low income. The utility function is normalized so that $U(2 L)=0$ and $U(2 H)=1$, and the third possible consumption level, $H+L$, is denoted by $u ; u \in[1 / 2,1)$ since $U$ is concave.

The only decision an agent makes in this economy concerns matching. A matching is stable if no unmatched pair of agents can increase each of their utilities by matching, taking into account the consequences for their descendants. ${ }^{3}$ A matching is strictly stable if any unmatched pair of agent characteristics would strictly decrease their utilities by matching (taking into account the consequences for their descendants).

In each period half the men and half the women have the attribute, independent of the matching. As a consequence, the distribution over characteristics is independent of the matching. In this case, in order to analyze equilibrium it is enough to describe the stable matchings.

\subsection{Matching}

Since the attribute is unproductive, and the distribution over offspring characteristics is independent of parents' characteristics, any matching positively assortative on income will clearly be stable. The assortative matching has high income men match with high income women and men with the attribute match with women with the attribute:

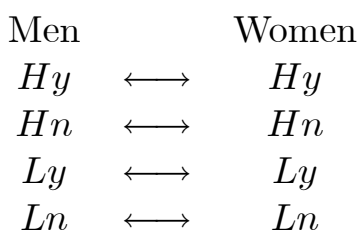

\footnotetext{
${ }^{3}$ Since there are no side payments, a matching will only be destabilized if both agents in an unmatched pair strictly prefer to match.
} 
An alternative interesting matching is the one shown below.

$\begin{array}{ccc}\text { Men } & & \text { Women } \\ H y & \longleftrightarrow & H y \\ H n & \longleftrightarrow & L y \\ \text { Ly } & \longleftrightarrow & H n \\ \text { Ln } & \longleftrightarrow & \text { Ln }\end{array}$

This matching is referred to as the mixed matching. As in the assortative matching, $H y$ 's match with $H y$ 's and $L n$ 's match with $L n$ 's, but unlike that matching, $H n$ 's match with $L y$ 's. The question of stability of this mixed matching immediately arises when the attribute is unproductive. Why would an $H n$ give up current consumption by matching with an $L y$, who contributes less to current consumption than an $H n$ ? Clearly, if the discount factor $\beta$ is 0 , that is, if parents care only about their personal consumption, mixed matching is not stable: an $H n$ man and an $H n$ woman would have higher utility by matching together than they would have if they followed the prescribed matching, whether or not other agents follow the mixed matching prescriptions.

However, if parents care about their children, there is a benefit to an $H n$ who matches with an $L y$ when all other agents are following the prescribed mixed matching. An $H n$ 's offspring will have the attribute with probability $1 / 2$ when matched with an $L y$, but with probability 0 if he or she matches with another $H n$. While the possession of this attribute doesn't affect the child's income, it does affect who they will match with. An $L y$ child will match with a high income agent $(H n)$, while an $L n$ child matches with an Ln. Consequently, if other agents are following the prescriptions of mixed matching, the attribute has value in affecting offsprings' matching prospects (and, a fortiori, consumption prospects) even when the attribute is nonproductive. The fact that the attribute has value because of its affect on matching doesn't ensure that the mixed matching is stable of course. Stability will be determined by the trade-off that an $H n$ faces between the lower current consumption that matching with an $L y$ entails and the expected benefit it will confer on his or her offspring. The more concave agents' utility function (that is, the greater the parameter $u$ is), the less is the loss in current consumption when an $H n$ agent matches with an $L y$, compared with the utility that would result from matching with another $\mathrm{Hn}$. In addition, the more weight parents put on their children's welfare (that is, the greater is $\beta$ ), the greater is the benefit to an $H n$ agent of matching with an $L y$ agent. We show in MP that mixed matching will be stable if

$$
u \geq \frac{4-3 \beta}{2(2-\beta)}
$$




\subsection{Productive Attributes}

The discussion above about the model in MP illustrates how different social arrangements (different matching patterns) are associated with different economic consequences: the variance of consumption is lower under mixed matching than under assortative matching. That discussion focussed on the case in which the attribute is nonproductive, that is, the attribute is completely independent of anything that enters directly into peoples' utility function. The focus on nonproductive asset case makes particularly clear how social arrangements can affect the value of an asset. If an attribute is productive (that is, it affects the probability that an individual will have high income), the attribute will naturally be valued. MP show that even in the case that an asset has direct value because it is productive, there may be additional value to the asset stemming from the social arrangements. Suppose, for example, that the attribute in

question is height. It may be that height has a productive component; for example, a tall person may be able to reach the top shelves in a storage closet without getting a ladder, thereby being able to do some tasks more quickly than a shorter person. In such a scenario, the attribute may lead to a higher probability of high income than would be the case in the absence of the attribute. All people would naturally prefer taller partners in such a world, even if height did not enter directly into utility functions, since people would realize that the children they have with tall partners are more likely to have high income than the children they have with short partners.

That the attribute may have additional social value can be seen as follow. Since the attribute is productive, people will prefer partners with the attribute to those without, all other things being equal. But if the productive advantage is small, there may be two stable matchings corresponding to those described above for the unproductive attribute case. One will have high income people without the attribute matching with like partners, and a second will have high income people without the attribute matching with low income people with the attribute. The situation is as before: it may be that the social arrangements in the society are such that if others in society value the attribute above and beyond its productive value, then it is rational of each individual to do so as well.

MP provide sufficient conditions under which both assortative matching and mixed matching are stable. The attribute will have greater value in the mixed matching case than in the assortative matching case; the increased value under mixed matching should be thought of as the social value of the asset, since it stems from the social arrangements that operate in that case. 


\subsection{Endogenous Attribute Choice}

We have seen above how the social arrangements in a society can affect individuals economic welfare. Agents in the model as described make no economic decisions; their only choice was whom to match with. MP extend the basic model to incorporate an economic decision and show that the economic decisions depend on the social arrangements in a society. We briefly describe that extension.

The model with productive assets is extended to allow parents to spend money to provide children who do not inherit the attribute some probability of acquiring the attribute. The last section described how the value of an exogenously allocated productive asset differed depending on the operative social arrangements. Social arrangements that lead to higher attribute value will then provide parents with a greater incentive to invest in the attribute for those children who have not inherited the attribute. Parents' response is then to invest more, leading to a higher proportion of people who have the attribute, and consequently, higher average income.

Another way of describing this last result is to say that a productive attribute such as education can have different returns in a society depending on the social arrangements within that society. There will be a direct economic return from investment in education that does not depend on social arrangements, but in addition there will be a social return investment in education that can depend on the social arrangements. If a large society is composed of several subsocieties, and each individual in a subsociety always matches with someone in the same subsociety, it may be possible for the subsocieties to be governed by different social arrangements. One may be governed by the social arrangement in which education is valued solely for its productive value, while a second may be governed by a social arrangement that has a social value in addition to the direct productive value. Even if the individuals in the two subsocieties face the same labor market, individuals in the second subsociety will, on average, acquire more education because of the social value. The possible difference in returns to investment in education that individuals face because of differences in social arrangements illustrates the usefulness of models that focus on multiple equilibria as the way in which the social environment affects economic decisions.

\section{References}

Becker, G. (1991): "A Note on Restaurant Pricing and Other Examples of Social Influences on Price," Journal of Political Economy, 99, 1109-1116.

Bisin, A., And T. Verdier (2000): "Beyond the Melting Pot: Cultural Transmission, Marriage, and the Evolution of Ethnic and Religious Traits," Quarterly Journal of Economics, 115, 955-988. 
Cole, H. L., G. J. Mailath, and A. Postlewaite (1992): "Social Norms, Savings Behavior, and Growth," Journal of Political Economy, 100, 1092-1125.

(1995): "Response to 'Aristocratic Equilibria'," Journal of Political Economy, 103, 439-443.

(1998): "Class Systems and the Enforcement of Social Norms," Journal of Public Economics, 70, 5-35.

Fernandez, R., A. Fogli, and C. Olivetti (2002): "Marrying Your Mom: Transmission of Preferences and Women's Labor Market and Education Choices," Discussion paper, New York University.

GreIF, A. (1993): "Contract Enforceability and Economic Institutions in Early Trade: The Maghribi Traders' Coalition," American Economic Review, 83(3), 525-548.

Landsburg, S. E. (1995): "Aristocratic Equilibria," Journal of Political Economy, 103, 434-438.

Mailath, G., And A. Postlewaite (2002): "Social Assets," Discussion paper, University of Pennsylvania. 